\title{
REGULAÇÃO DA ENERGIA PRÉ-PAGA NO BRASIL E OS DIREITOS DOS CONSUMIDORES
}

\section{Sergio Guerra}

Pós-Doutor em Direito (Visiting researcher na Yale Law School), Pós-Doutor em Administração Pública. Doutor e Mestre em Direito. Diretor e professor titular de Direito Administrativo da Fundação Getulio Vargas Direito Rio, nos cursos de graduação e mestrado. Editor da Revista de Direito Administrativo. Coordenador-geral do Curso Internacional Business Law da University of California - Irvine, EUA. Embaixador da Yale University no Brasil. Vogal da Comissão de Arbitragem e árbitro da Câmara Fundação Getulio Vargas de Mediação e Arbitragem. Árbitro da Câmara de Arbitragem da Federação da Indústria do Paraná e do Centro Brasileiro de Mediação e Arbitragem - CBMA. Consultor jurídico da Comissão de Direito Administrativo da OAB/RJ.

\section{Rafaela Nogueira}

Doutora e Mestre pela Escola Brasileira de Economia e Finanças da Fundação Getulio Vargas Direito Rio. Professora e pesquisadora da Fundação Getulio Vargas Direito Rio.

Resumo: A modalidade de prestação do serviço público de distribuição de energia pré-paga tem sido implementada com sucesso na experiência internacional, seguindo novas tecnologias e inovações. Esta tem se apresentado como sendo uma interessante modalidade de cobrança de tarifa por apresentar vantagens consideráveis para empresas e para usuários ou consumidores, notadamente por trazer maior previsibilidade no valor da conta de consumo, além de apresentar maior racionalidade no consumo da energia elétrica. No Brasil, a modalidade de cobrança tarifária foi regulamentada em 2014, por normativa expedida pela Agência Nacional de Energia Elétrica (ANEEL). Em que pese a normatização, esta modalidade de cobrança tarifária não foi implementada pelas empresas concessionárias. A hipótese examinada no presente artigo, sob vieses econômico e jurídico, é a de que a não implementação se deve ao alto risco antevisto pelos fornecedores de que, em caso de suspensão do serviço de distribuição de energia elétrica, por não pagamento, os consumidores irão questionar judicialmente a interrupção do serviço por afronta a direitos fundamentais. Caso comprovada a hipótese, em bases empíricas, esse fenômeno constataria a ideia de que há correlação direta entre o excesso de proteção aos direitos dos consumidores e os efeitos negativos causados a eles próprios, o que justificaria a importância da função de regulação para a manutenção do equilíbrio sistêmico.

Palavras-chave: Serviço público. Regulação. Energia elétrica. Pré-pagamento. Direito do Consumidor.

Sumário: 1 Introdução - 2 Projeto-piloto do sistema de energia elétrica pré-pago no Brasil - 3 Evidências econômicas na adoção do sistema pré-pago sobre a receita das empresas e o consumo - 4 Dados do contexto brasileiro sobre a judicialização do tema de suspensão de consumo de energia elétrica por inadimplemento - $\mathbf{5}$ Comparação com a telefonia móvel - $\mathbf{6}$ Dos fundamentos para a implantação efetiva do sistema pré-pago e os direitos dos consumidores do serviço público de distribuição de energia elétrica - 7 Conclusão - Referências. 


\section{Introdução}

A Agência Nacional de Energia Elétrica (ANEEL) instaurou o processo de Consulta Pública de número 016, em 12 de dezembro de 2017, relativamente à modalidade de pré-pagamento do serviço público de distribuição de energia elétrica no Brasil. 0 objetivo desta consulta pública era o de examinar, com a sociedade e players do setor, ${ }^{1}$ sob a óptica sistêmica da função de regulação, ${ }^{2}$ a pertinência da normatização do sistema de pré-pagamento de consumo de energia elétrica, analisando-se os eventuais obstáculos para a sua implantação, assim como as propostas de aprimoramentos da Resolução Normativa no 610/2014.

Esta Resolução foi produto da Audiência Pública 048 (“AP 048”) realizada pela ANEEL, em 2012. O objetivo era diminuir os encargos no sistema brasileiro de energia elétrica, dispondo que as distribuidoras recorressem à modalidade de pré-pagamento pelo consumo de energia elétrica. Entretanto, apesar das alegadas vantagens desse sistema - incluindo a possibilidade de redução das chamadas perdas não técnicas de energia, mais conhecidas como furto e fraude de energia ${ }^{3}$ o serviço não foi implementado até o momento, aparentemente por desinteresse das empresas.

De acordo com os dados do Projeto Regulação em Números ${ }^{4}$ da Fundação Getulio Vargas, do ponto de vista quantitativo, as demandas das empresas na Audiência Pública 048 - que resultou na criação da Resolução Normativa no $610 / 2014$ - foram mais atendidas do que as demandas dos consumidores e, no entanto, as empresas ainda não ofertam o serviço de energia pré-paga no Brasil.

1 Operadoras e suas entidades representativas, prestadores e suas entidades representativas, atores governamentais e suas entidades representativas. Neste sentido, ver SALINAS, Natasha; MARTINS, Fernanda. Os Mecanismos de Participação da Agência Nacional de Saúde Suplementar (ANS). No prelo.

2 Sobre a função de regulação, ver GUERRA, Sérgio. Discricionariedade, regulação e reflexividade: uma nova teoria sobre as escolhas administrativas. 5. ed. Belo Horizonte: Fórum, 2018.

3 “O furto e a fraude de energia são considerados como perdas não-técnicas e também impactam diretamente as tarifas de energia elétrica, uma vez que uma parte destas é rateada entre todos aqueles da área de concessão. Anualmente, essas perdas consomem aproximadamente 8 bilhões de reais de prejuízo à sociedade: governo, empresas distribuidoras e consumidores. Portanto, assim como a redução da inadimplência, a diminuição das perdas não-técnicas se traduz em benefícios para distribuidoras e consumidores" (Nota Técnica nº 014/2012 - SRC/ANEEL).

4 "O projeto Regulação em Números tem como objetivo construir bases de dados sobre Agências Reguladoras Federais que permitirão: 1. Reunir e sistematizar informações sobre as atividades desenvolvidas pelas agências; 2. Tornar estas informações acessíveis e transparentes ao público em geral, para que sejam utilizadas com os mais diferentes propósitos (pesquisa aplicada e acadêmica, acesso à informação, etc.); 3. Gerar relatórios com análises quantitativas e qualitativas dos dados coletados, ampliando o conhecimento científico sobre a atuação das agências." Disponível em: https://direitorio.fgv.br/projetos/ regulacao-em-numeros. Acesso em: 6 jun. 2018. 
Os dados mostram que a AP 048 teve 153 contribuintes que apresentaram 345 contribuições no total. Destas, 180 ( $52 \%$ do total) eram provenientes de pessoas jurídicas, 153 (44\%) de pessoas físicas e em 12 (4\%) não identificamos a origem da contribuição. Além disso, dos participantes totais, 11 ( $7 \%$ do total) pertencem à categoria de agente econômico regulado, 11 (7\%) se referem a consumidor ou usuário, 1 (1\%) a ator governamental e 130 (85\%) em que não houve identificação. Das 345 contribuições apresentadas apenas 48 (14\%) foram aceitas.

De acordo com o relatório de análise das contribuições referentes à AP 048, das aceitas, 21 (44\% do total de aceitas) foram apresentadas por distribuidoras enquanto 16 (33\%) foram apresentadas por indivíduos interessados, e 11 (23\%) apresentadas por outros. Porém, apesar de a Resolução Normativa no 610/2014 da ANEEL contar com mais contribuições aceitas de distribuidoras do que consumidores - o que, de certa forma, aparenta beneficiar essas empresas - e permitir a implantação da modalidade de pré-pagamento pelo consumo energia elétrica, o serviço não se encontra operante no Brasil até hoje.

Analisando pela óptica do ofertante, pode-se inferir que a não operacionalidade da modalidade pré-paga indica que não deve ser vantajoso economicamente fazêla. Se fosse vantajoso para as empresas, o serviço provavelmente já estaria sendo oferecido. Por outro lado, analisando pela perspectiva do consumidor, resta indagar se haveria demanda da modalidade sob a forma de energia pré-paga.

De acordo com o Projeto do Regulação em Números, cinco anos depois da audiência de criação do sistema, na consulta pública aberta em dezembro de 2017, $43,9 \%$ dos participantes eram referentes a consumidores interessados e 12,2\% referentes às empresas geradora, distribuidora e transmissora. 0 percentual total de participantes na consulta pública está representado na Tabela 1. 
TABELA 1

Subcategoria Participante

\begin{tabular}{lr}
\hline \hline Indivíduo Interessado & $43,90 \%$ \\
Geradora Distribuidora Transmissora & $12,20 \%$ \\
Distribuidora & $9,76 \%$ \\
Conselho de Consumidores da Concessionária & $7,32 \%$ \\
Entidade Sindical & $4,88 \%$ \\
Geradora Distribuidora & $4,88 \%$ \\
Organização da Sociedade Civil & $4,88 \%$ \\
Geradora & $2,44 \%$ \\
Geradora Comercializadora & $2,44 \%$ \\
Geradora Transmissora & $2,44 \%$ \\
Infraestrutura & $2,44 \%$ \\
Poder Executivo Estadual & $2,44 \%$
\end{tabular}

Fonte: Elaboração própria (Regulação em Números FGV)

$\mathrm{Na}$ Tabela 1, as distribuidoras de energia elétrica figuram em terceiro lugar em número de participações, com 9,8\%. Em quarto lugar está o conselho de consumidores da concessionária, com 7,3\% das participações.

É fácil notar que, na consulta pública aberta em 2017, a maior parte dos participantes era de pessoas físicas, fato este que evidencia algum tipo de interesse por parte dos consumidores quanto à implementação da energia prépaga. Assim, apesar de não podermos afirmar empiricamente que há demanda por parte de consumidores, é justo inferir que há algum indicativo de interesse da classe. $^{5}$

Com efeito, o referido ato administrativo da ANEEL instituindo a cobrança pré-paga de energia elétrica surgiu como forma de se buscar equacionar um dos maiores problemas que afetam a relação entre consumidores ${ }^{6}$ e distribuidoras de

5 Ainda, um dado relevante é saber quantas contribuições foram feitas e quem teve mais contribuições aceitas. No entanto, até o término do presente artigo, o relatório sobre a consulta pública realizada pela ANEEL ainda não havia sido concretizado.

6 Adotaremos, para efeito deste artigo, o termo "consumidor" mesmo diante de já ter sido editado o Código de Defesa do Usuário (Lei no 13.460/2017). Mesmo antes da edição da lei, parte da doutrina e da jurisprudência já separavam as figuras dos consumidores e usuários de serviços públicos. Nesse sentido, indicamos a obra: "Serviços Públicos e Direito do Consumidor: Possibilidades e Limites da Aplicação do 
energia elétrica: a inadimplência, sendo esta considerada o consumo faturado, e não o recebido pela distribuidora.

Sabe-se que parte da inadimplência é tolerada e refletida nos contratos de concessão como receita irrecuperável, ${ }^{7}$ sendo, inclusive, computada na composição das tarifas de modo a não afetar o equilíbrio econômico e financeiro da concessão. No entanto, segundo a Nota Técnica no 014/2012 - SRC/ANEEL, têm sido recorrentes os casos em que os índices de inadimplência superam os limites de receita irrecuperável previstos pela ANEEL. A inadimplência ainda é causa das chamadas perdas não técnicas.

Com relação aos efeitos dessa inadimplência aos consumidores, estes estão sujeitos ao endividamento em si e, o que é mais sensível, à suspensão (corte) do fornecimento de energia elétrica.

Dado que a experiência internacional apresenta casos de sucesso, como o Reino Unido, ${ }^{8}$ onde há diversas companhias que já ofertam o sistema de distribuição de energia pré-paga, a hipótese examinada no presente artigo é a de que a não implementação se deve ao alto risco antevisto pelos concessionários fornecedores. Em caso de suspensão do serviço de distribuição de energia elétrica por falta de pagamento, parte significativa dos consumidores questionaria judicialmente a interrupção do serviço por alegada afronta a direitos fundamentais e muito provavelmente lograriam êxito no Poder Judiciário.

Casocomprovadaahipótese, metodologicamenteenfrentadamajoritariamente em bases empíricas, o fenômeno constataria haver correlação direta entre as medidas que tragam excesso de proteção aos direitos dos consumidores e os efeitos negativos causados a elas próprias, o que justificaria a importância da função de regulação para a manutenção do equilíbrio sistêmico.

0 presente artigo traz inovação à literatura existente, na medida em que analisa com profundidade aspectos sob o viés jurídico-econômico acerca da implementação e aprimoramento da modalidade de pré-pagamento de energia elétrica no país. Os artigos pregressos, ${ }^{9}$ até então, tomaram como dado apenas o

CDC", artigo de Alexandre dos Santos Aragão publicado na REDAE, em 2008, e o acórdão do Superior Tribunal de Justiça REsp no 840.864 - SP (2006/0078247-0). Voto Min. Eliana Calmon.

7 "O montante relacionado às receitas irrecuperáveis que é considerado na receita requerida da distribuidora é definido a partir da mediana dos percentuais reais de receitas irrecuperáveis das empresas para cada classe de consumo e o grupo ou cluster em que esta se encontra" (Nota Técnica no 014/2012 - SRC/ ANEEL).

8 Nota Técnica no 014/2012 - SRC/ANEEL, de 19.06.2012.

9 CASARIN, Ariel; NICOLLIER, Luciana. Prepaid meters in electricity. A cost-benefit analysis. In: MARQUEZ, Patricia; RUFIN, Carlos (Coord.). Private Utilities and Poverty Alleviation: Market Initiatives at the Base of the Pyramid. Williston, USA: Edward Elgar Publishing Inc, 2011, p. 108-133.; BRUTSCHER, PhilippBastian. Payment Matters? - An Exploratory Study into the Pre-Payment Electricity Metering, 2011. Working Paper EPRG1108. Cambridge, UK: Electricity Policy Working Group, Cambridge University. Disponível 
processo normativo das suas respectivas agências reguladoras e, a partir destes dados, realizaram suas inferências. Este artigo, diversamente, intenta compreender sob olhares econômico e jurídico como esse processo se desenvolveu desde sua origem e as razões para sua inoperância atual.

O artigo encontra-se dividido da seguinte forma: na Seção 1, será analisada a primeira experiência brasileira com a adoção do sistema pré-pago de energia. Na Seção 2, serão estudadas as evidências econômicas na adoção do sistema prépago sobre a receita das empresas e o consumo. Na Seção 3, serão verificados os dados no contexto brasileiro sobre a judicialização da suspensão da distribuição de energia elétrica em casos de inadimplência dos consumidores. Na Seção 4, será realizada uma comparação com a telefonia móvel ${ }^{10}$ que já adotou o sistema pré-pago. Na quinta e última seção, serão expostos os fundamentos para a implantação efetiva do sistema pré-pago e os direitos dos consumidores do serviço público de distribuição de energia elétrica, seguidos da conclusão deste trabalho.

\section{Projeto-piloto do sistema de energia elétrica pré-pago no Brasil ${ }^{11}$}

A experiência internacional evidencia que a implementação da energia prépaga apresentou diversas vantagens, tais como redução da inadimplência e do próprio corte de energia elétrica. ${ }^{12}$ Diante disso, cumpre investigar os antecedentes e por que não foi implementado no Brasil.

em: https://www.repository.cam.ac.uk/handle/1810/241889. Acesso em: 6 jun. 2018; MALAMA, Albert; MUDENDA, Priscilla; NG'OMBE, Austine; MAKASHINI, Lilias; ABANDA, Henry. The Effects of the Introduction of Prepayment Meters on the Energy Usage Behaviour of Different Housing Consumer Groups in Kitwe, Zambia. AIMS Energy, v. 2, n. 3, p. 237-259, 2014. Disponível em: http://www.aimspress. com/fileOther/PDF/energy/20140303.pdf. Acesso em: 10 jun. 2019; ESTEVES, Gheisa Roberta Telles; OLIVEIRA, Fernando Luiz Cyrino; ANTUNES, Carlos Henggeler; SOUZA, Reinaldo Castro. An overview of electricity prepayment experiences and the Brazilian new regulatory framework. In: Renewable and Sustainable Energy Reviews, v. 54, p. 704-722, 2016. Disponível em: https://www.sciencedirect.com/ science/article/pii/S1364032115010680. Acesso em: 6 jun. 2018.

10 A comparação com a telefonia móvel tem por objetivo compreender a racionalidade por trás do uso do mecanismo de pré-pagamento de outro mercado que, em que pese suas especificidades, teve a consolidação do uso do cartão pré-pago.

11 Dados disponíveis na Nota Técnica no 014/2012 - SRC/ANEEL, de 19.06.2012.

12 No Reino Unido, o aumento do número de medidores pré-pagos coincide com a queda das desconexões, dado que o método pré-pago passou a ser visto como a solução para os problemas relativos a dívidas. Em 2015, apenas cerca de 200 famílias foram desconectadas da rede elétrica por dívida. Ainda, os métodos pré-pagos não são exclusivos de famílias de baixa-renda, ainda que esse grupo seja maioria dentre os usuários. Em Moçambique, por sua vez, a energia pré-paga começou a ser ofertada em 1995, pela empresa estatal EDM, sendo o nome do sistema de venda de energia elétrica pré-paga no país CREDELEC. Sua implementação se iniciou como uma solução para o problema de fluxo de caixa (decorrente de alta inflação e dificuldades econômicas), uma vez que o governo e a empresa pública perceberam ser 
Em 2011, ao promover um seminário sobre o pré-pagamento de energia elétrica a ANEEL iniciou os estudos e, no mesmo ano, autorizou a Central Elétrica do Pará (Celpa) e a Eletrobras Amazonas a implantar um sistema de pré-pagamento de energia elétrica. 0 projeto-piloto alcançou comunidades isoladas no Pará e no Amazonas, beneficiando, à época, mais de 430 famílias, que foram atendidas por mini usinas fotovoltaicas.

A ANEEL visitou quatro comunidades isoladas localizadas no Município de Maués (AM) com o objetivo de verificar a aplicação do modelo de pré-pagamento de energia elétrica, conferir a repercussão do projeto perante a população das áreas atendidas e atestar o monitoramento remoto das mini usinas de energia fotovoltaicas pela distribuidora local. Em todas as localidades visitadas o grau de satisfação dos consumidores com o atendimento das mini usinas, e com o sistema de pré-pagamento, foi elevado. ${ }^{13}$

politicamente difícil aumentar as tarifas, tendo em vista a população em sua maioria pobre no contexto do pós-guerra. Além disso, também foi visto como solução a dois problemas usuais do país: o furto de eletricidade e cortes de energia por ausência de pagamento. Em relação a todo o território do país, o percentual de consumidores que se utilizam do sistema pré-pago é de $86 \%$. No entanto, de acordo com BAPTISTA, Idalina. 'We Live on Estimates': Everyday Practices of Prepaid Electricity and the Urban Condition in Maputo, Mozambique. In: International Journal of Urban and Regional Research, v. 39, n. 5, p. 1004-1019, 2015. Disponivel em: https://onlinelibrary.wiley.com/doi/full/10.1111/1468-2427.12314. Acesso em: 6 jun. 2018. Apenas estimados 16\% do total da população de Moçambique tinha acesso à eletricidade no ano de 2010. Esse acesso é desnivelado regionalmente, dado que partes urbanas têm maior acesso à eletricidade. Nos EUA, o sistema de pré-pagamento é marcante apenas no Arizona e no Texas. Porém, em todos os casos, a economia de energia é de cerca de $12 \%$ para o consumidor - ao ser notificado sobre o uso e período de energia e, sabendo o quanto foi subtraído de seu saldo, os usuários se tornam radicalmente mais conscientes sobre o uso da eletricidade. Nas províncias de Panamá e Colón, no Panamá, mais de 11.500 famílias são clientes dos planos de energia pré-paga. Desde 2012, empresas provedoras como a Elektra Noreste S.A. (ENSA) - uma das empresas do grupo EPM, que aplica projeto similar em Medellín, Colômbia - optam pela instalação de medidores de energia. De acordo com Autoridade Nacional de Serviços Públicos do Panamá, existe certa rejeição por parte dos clientes que se encontravam em estado irregular, que anteriormente não tinham condições de acesso ao serviço e se conectavam ilegalmente à rede. Porém, a provedora Unión Fenosa já destacou a enorme redução do inadimplemento, dado que em bairros como Viejo Veranillo (onde mais de $90 \%$ dos usuários não pagavam luz), na Cidade do Panamá, no final do ano de 2016, mais de 2 mil famílias já haviam sido incluídas nos projetos de pré-pagamento de energia. Por fim, na Colômbia, o projeto da distribuidora Empresa Pública de Medellín (EPM) foi formulado para atender a 35 mil famílias em cinco anos, mas o sucesso foi tamanho que hoje esse número chega a 112 mil famílias só em Medellín - e mais de 240 mil em todo o departamento de Antioquia. No departamento de Santander, a empresa ESSA vem implementando o programa em áreas carentes, a fim de dar um passo na regularização da distribuição de energia; mais de 800 famílias foram beneficiadas com o pré-pagamento de energia. Os projetos para a energia elétrica na Colômbia são grandes: estima-se que em oito anos $95 \%$ dos usuários do serviço deverão ter um sistema de medição de energia avançado - e, possivelmente, terão acesso ao pré-pagamento de energia ( Dados disponíveis na Nota Técnica ํํ0121/2017-SRD/ANEEL, de 12.12.2017 e na Nota Técnica ํํ014/2012 SRC/ANEEL, de 19.06.2012).

13 Disponivelem:http://www2.aneel.gov.br/aplicacoes/noticias/Output_Noticias.cfm?ldentidade=5730\&id_ area $=90$. Acesso em: 6 jun. 2018. 
Cumpre registrar que, anteriormente, as comunidades não eram atendidas pela distribuidora, sendo o suprimento existente viabilizado por meio de geradores movidos a óleo diesel. O suprimento, neste caso, era restrito ao horário de funcionamento das escolas ( $18 \mathrm{~h}$ às $22 \mathrm{~h}$ ). Os moradores das comunidades recebiam uma cota de óleo das prefeituras, arcando em média com $R \$ 25,00$ além da cota gratuita para atender às suas necessidades. No sistema de prépagamento os consumidores passaram a gastar entre $\mathrm{R} \$ 5,00$ e $\mathrm{R} \$ 10$ por mês para manter a energia disponível durante as 24 horas do dia nas suas unidades consumidoras.

A ANEEL constatou também uma elevada consciência e percepção do custo da energia por parte dos consumidores. A maioria deles sabia o consumo médio mensal dos eletrodomésticos e quanto eles consumiam diariamente. Segundo a ANEEL, a população adequou seus hábitos de consumo ao preço da energia e à sua capacidade de pagamento. Os motivos para o consumo racional podem ser explicados pela existência de um mostrador digital dentro das residências, pela possibilidade de comprarem somente o necessário para seu consumo e pelo ato de inserir os créditos no medidor. Nenhuma das famílias entrevistadas pôde relatar sobre a sinalização (visual ou sonora) referente ao esgotamento do crédito, pois não tiveram o fornecimento suspenso por falta de pagamento e nem deixaram que o consumo chegasse ao limite que faz emitir o sinal.

$\mathrm{Na}$ gestão do projeto-piloto, a distribuidora Eletrobras Amazonas firmou convênios com as prefeituras municipais, pelos quais agentes de saúde ou professores das comunidades ficaram responsáveis pela venda dos créditos. Em todas as comunidades atendidas foi possivel verificar o monitoramento da usina e a comunicação remota do ponto de venda com o sistema comercial da empresa em Manaus. Também foi disponibilizado, além do fornecimento de energia, um ponto de conexão de internet via satélite pelo programa Governo Eletrônico Serviço de Atendimento ao Cidadão (Gesac), do Ministério das Comunicações. ${ }^{14}$

Os principais benefícios pretendidos pela Agência com o pré-pagamento são: (1) a redução de custos operacionais (leitura, emissão e entrega de faturas, suspensão e religação de unidades consumidoras) por parte da distribuidora; (2) a diminuição da inadimplência dos consumidores em razão da compra antecipada de energia; (3) o aumento da satisfação do consumidor, dado que haverá redução de intervenções da fornecedora de energia; (4) a melhoria do gerenciamento do consumo de energia com o controle dos gastos do consumidor no ato da compra; (5) uma maior transparência em relação aos gastos diários por meio de

14 Disponível em: https://www.governodigital.gov.br/cidadania/inclusao-digital/programa-gesac. Acesso em: 6 jun. 2018. 
informações via medidor; (6) a economia no consumo de energia mediante uma mudança dos hábitos dos consumidores; (7) a eliminação da cobrança de taxas de corte e religação; (8) o fim de inconvenientes gerados por erros de leitura, faturamentos por estimativa, cortes indevidos e problemas de religação fora do prazo; e (9) a flexibilidade na aquisição e no pagamento da energia.

No entanto, o projeto-piloto da Celpa foi desativado. Apenas a experiência da Eletrobras Amazonas Energia, em comunidades isoladas do Amazonas, deu certo de acordo com a ANEEL.

\section{Evidências econômicas na adoção do sistema pré-pago sobre a receita das empresas e o consumo}

A modalidade de energia pré-paga implica compra de créditos para utilização do bem. Ou seja, para poder ter energia elétrica em sua residência o consumidor precisa pagar previamente pela quantidade a ser ainda utilizada. Ademais, um sistema sonoro e luminoso avisará quando os créditos estiverem próximos de acabar, de modo que o consumidor não seja surpreendido quando seus créditos findarem. Para evitar a interrupção total do serviço quando acabarem os créditos, o consumidor terá de contratar o crédito de emergência.

As vantagens dos planos pré-pagos incluiriam ainda uma melhor administração do débito e do uso da energia pelos consumidores, possibilitando um uso mais racional da energia, além de permitir maior previsibilidade orçamentária. As possíveis desvantagens seriam falta de acesso às melhores opções de preço no mercado, inconveniência de se recarregar a chave ou o cartão e, principalmente, corte da eletricidade em caso de ausência de recarga.

Casarin e Nicollier (2008) ${ }^{15}$ usaram a análise custo-benefício para avaliar a adoção de medição de energia pré-paga. 0 trabalho enfatiza como o papel de tarifas, o custo de investimentos iniciais e as características socioeconômicas da população afetam o desempenho do sistema. Os resultados da pesquisa indicam que medidores de pré-pagamentos levam ao aumento no bem-estar. Também indicam que as vantagens do sistema estão associadas à redução dos atrasos nas contas a receber, dos custos operacionais e financeiros por parte da empresa provedora de serviço e uma melhor alocação de recursos para o usuário.

15 CASARIN, Ariel; NICOLLIER, Luciana. Prepaid meters in electricity. A cost-benefit analysis. In: MARQUEZ, Patricia; RUFIN, Carlos (Coord.). Private Utilities and Poverty Alleviation: Market Initiatives at the Base of the Pyramid. Williston, USA: Edward Elgar Publishing Inc, 2011, p. 108-133. 
O artigo de Brutscher (2011) $)^{16}$ mostra que famílias que pagam sua eletricidade antecipadamente tendem a consumir menos eletricidade do que aquelas que pagam posteriormente. Uma pesquisa realizada na Zâmbia por Malama et al $(2014)^{17}$ sobre os efeitos de se introduzir medidores de pré-pagamento no comportamento de consumo de energia dos consumidores domésticos concluiu que há uma satisfação geral com a introdução de medidores. O controle das despesas e o fato de não haver litígios nas faturas foram as principais razões para esse ganho de satisfação. Muitas famílias também relataram melhora em seu orçamento para eletricidade, e parece ter ocorrido uma queda no número de domicílios com dívidas históricas.

Esteves et al (2016) $)^{18}$ definem quatro diretrizes fundamentais para o sucesso da introdução dos sistemas de pré-pagamento: i) definição do grupoalvo; ii) tecnologia de medição e padronização de procedimentos; iii) logística de pontos de venda; iv) questões de defesa do consumidor. Este último item dialoga diretamente com as pesquisas desenvolvidas para a verificação da hipótese deste estudo, conforme será mostrado mais adiante.

Sob um olhar econômico, e com base nas pesquisas realizadas, conclui-se pela comprovação de benefícios para o sistema de distribuição de energia elétrica, com ganhos tanto para concessionárias prestadoras de serviço público quanto para os consumidores.

\section{Dados do contexto brasileiro sobre a judicialização do tema de suspensão de consumo de energia elétrica por inadimplemento}

A literatura já identificou que a possibilidade de redução do nível de inadimplência e dos custos para realização da leitura são os motivadores preponderantes do ponto de vista das distribuidoras. Já sob a perspectiva do

16 BRUTSCHER, Philipp-Bastian. Payment Matters? - An Exploratory Study into the Pre-Payment Electricity Metering. 2011. Working Paper EPRG1108. Cambridge, UK: Electricity Policy Working Group, Cambridge University. Disponível em: https://www.repository.cam.ac.uk/handle/1810/241889. Acesso em: 6 jun. 2018.

17 MALAMA, Albert; MUDENDA, Priscilla; NG'OMBE, Austine; MAKASHINI, Lilias; ABANDA, Henry. The Effects of the Introduction of Prepayment Meters on the Energy Usage Behaviour of Different Housing Consumer Groups in Kitwe, Zambia. AIMS Energy, v. 2, n. 3, p. 237-259, 2014.

18 ESTEVES, Gheisa Roberta Telles; OLIVEIRA, Fernando Luiz Cyrino; ANTUNES, Carlos Henggeler; SOUZA, Reinaldo Castro. An overview of electricity prepayment experiences and the Brazilian new regulatory framework. In: Renewable and Sustainable Energy Reviews, v. 54, p. 704-722, 2016. Disponível em:

https://www.sciencedirect.com/science/article/pii/S1364032115010680. Acesso em: 6 jun. 2018. 
consumidor, a opção pelo pré-pagamento advém da possibilidade de melhor gerir o consumo e facilitar o pagamento de sua fatura. ${ }^{19}$

Conforme previamente mencionado, a Resolução Normativa no 610/2014 já disciplina o modelo para o oferecimento de energia pré-paga no Brasil. Entretanto, como esta modalidade ainda não está sendo oferecida pelas concessionárias distribuidoras de energia elétrica faz-se necessário levar em consideração uma particularidade no caso brasileiro: o receio da judicialização decorrente da interrupção automática de energia elétrica em caso de não aquisição prévia de energia elétrica pelos consumidores.

A interrupção do fornecimento de serviço público por inadimplemento do consumidor foi, no passado, bastante polêmica não só no que se refere à distribuição de energia elétrica, mas também na distribuição de água ou utilização de linhas telefônicas.

O receio da judicialização pelas empresas não é de todo injustificado. Ao realizarmos uma pesquisa jurisprudencial pelo site Digesto $^{20}$ foi possível constatar que, dos processos concluídos em 2017, grande parcela discutia a interrupção de energia elétrica e a suspensão do seu fornecimento. Por exemplo, 92,6\% dos processos relacionados à energia elétrica no Superior Tribunal de Justiça (STJ) tiveram como tema a interrupção no fornecimento de energia elétrica. ${ }^{21}$

Os dados relativos à judicialização da temática utilizando-se a chave "corte de energia elétrica" não são desprezíveis, trazendo certa insegurança jurídica que impacta na estratégia empresarial das concessionárias em ofertar energia pré-paga, notadamente tendo-se em conta uma das principais características desse sistema é a celeridade no corte (automático) de energia nos casos de inadimplemento.

Mesmo com a existência desses motivadores, um aspecto relevante - e que já foi considerado bastante polêmico - consistia em saber se seria jurídico que as concessionárias de serviços públicos suspendessem o fornecimento de energia elétrica, água ou telefone, na hipótese de inadimplemento dos respectivos consumidores. O tema da suspensão de fornecimento é importante na medida em que poderia inibir a implementação do sistema de pré-pagamento pelas empresas, haja vista que uma das maiores características desse novo sistema

\footnotetext{
Ver Nota Técnica no 0121/2017-SRD/ANEEL.

Disponível em: https://www.digesto.com.br/digesto/. Acesso em: 6 jun. 2018.

1 Este resultado foi alcançado a partir do seguinte método: realizamos, inicialmente, uma busca pelas palavras "energia elétrica" no ano de 2017. Em seguida, realizamos uma nova busca pelas palavras "energia elétrica interrupção no fornecimento". A partir destes dois resultados, foi possível chegar no resultado de $92,6 \%$.
} 
seria a celeridade no corte de energia quando confirmado o término dos créditos adquiridos pelo usuário.

A suspensão do fornecimento de energia elétrica ante o inadimplemento era um assunto permeado de insegurança jurídica, com posicionamentos doutrinários e jurisprudenciais conflitantes. Havia casos em que poderia haver suspensão do serviço público, remunerado mediante tarifa, em caso de não pagamento. No entanto, havia igualmente possibilidades em que o serviço prestado, mesmo ante o inadimplemento, deveria ser contínuo e ininterrupto.

O tema foi pacificado. A ANEEL previu a necessidade de uma regulação mais específica no que se refere ao sistema elétrico brasileiro, publicando a Resolução no 456/2000, revogada pela Resolução Normativa no 414/2010. Com a edição da Resolução no 414/2010 os tópicos da Resolução no 456/2000, diferentes assuntos abordados foram fragmentados em capítulos e a suspensão do fornecimento de energia elétrica do consumidor mereceu capítulo próprio (“Capítulo XIV - Suspensão do Fornecimento”).

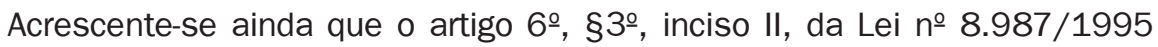
reconhece expressamente a legalidade da suspensão do fornecimento de energia elétrica quando o consumidor não cumpre com a obrigação de pagar pelo serviço público. ${ }^{22}$

Consoante se depreende do quadro legal que versa sobre a suspensão, tanto a legislação ordinária quanto as resoluções editadas pela ANEEL são uníssonas em admitir a suspensão do fornecimento de energia elétrica diante da inadimplência do consumidor, considerando, nesse caso, o interesse da coletividade (impacto sistêmico). ${ }^{23}$

Entretanto, o ordenamento jurídico também estabelece condicionantes para a interrupção do fornecimento de energia, de tal modo que essa não pode ser levada a efeito de acordo com a simples conveniência da delegatária. Pelo contrário, há, pelo menos, duas formalidades legais que devem ser observadas pelas prestadoras: o aviso prévio e a atualidade do débito.

Inicialmente, destaca-se que a suspensão do fornecimento deve ser precedida de comunicação ao consumidor, em, no mínimo, 15 dias (art. 173, I, “b”, RN no

22 Esta hipótese, como já mencionado, também está tratada pela atualmente vigente Resolução Normativa no 414/2010 da ANEEL, mais precisamente, em seu artigo 172, nos mesmos moldes do que foi antes preceituado pelo artigo 91 da Resolução no 456/2000, já revogada.

23 Salvo as hipóteses legais do Código de Defesa do Consumidor (CDC) “Art. 22. Os órgãos públicos, por si ou suas empresas, concessionárias, permissionárias ou sob qualquer outra forma de empreendimento, são obrigados a fornecer serviços adequados, eficientes, seguros e, quanto aos essenciais, contínuos. Parágrafo único. Nos casos de descumprimento, total ou parcial, das obrigações referidas neste artigo, serão as pessoas jurídicas compelidas a cumpri-las e a reparar os danos causados, na forma prevista neste código". Disponível em: http://www.planalto.gov.br/ccivil_03/Leis/L8078.htm. Acesso em: 6 jun. 2018. 
414/2000), com o desiderato de que Ihe sejam oportunizados o contraditório e a ampla defesa, princípios constitucionais assegurados pelo artigo 5으, inciso LV, da Constituição Federal. Este aviso prévio deve informar ao consumidor de forma clara e discriminada que determinada fatura relativa ao mês de consumo encontrase pendente de pagamento e que, em razão do inadimplemento, a interrupção do fornecimento de energia elétrica de sua residência pode ser efetivada pela concessionária ao término do prazo estipulado.

Concernente ao segundo requisito para se considerar legal a suspensão, qual seja, a necessidade da atualidade do débito, a jurisprudência majoritária já se posicionou quanto ao tema no sentido de que é imprescindivel essa condição para configurar a legalidade da interrupção. Assim, não pode a delegatária proceder à interrupção em razão de débitos pretéritos, por afronta ao artigo 42 do $\mathrm{CDC},{ }^{24}$ sendo indispensável a existência de débito relativo ao mês de consumo. Inexiste critério objetivo específico para caracterizar a dívida como pretérita, mas considera-se que, em média, após 90 dias do vencimento da fatura o débito pode ser considerado pretérito e, portanto, não pode a concessionária cessar o fornecimento em razão do inadimplemento de fatura que se venceu há mais de três meses.

A jurisprudência do STJ se alinhou e deu contornos à atualmente já pacificada orientação que permite o corte em razão do inadimplemento, ressalvadas algumas circunstâncias que gravitam em torno da inadimplência. Ademais, a jurisprudência também se consolidou quanto à impossibilidade de interrupção de energia elétrica em casos de cobranças pretéritas. ${ }^{25}$

Apesar de ser um tema já pacificado, a judicialização sobre o tema da energia elétrica ainda é bastante relevante. O sítio eletrônico Digesto, atualizado diariamente, espelha as decisões do Judiciário brasileiro. A base formulada para o presente artigo foi constituída por meio da busca de palavras-chaves no site, onde é possível realizar buscas jurisprudenciais.

A primeira busca que realizamos no site foi pela palavra "consumidor". Ou seja, buscamos processos concluídos em 2017, no Tribunal de Justiça de São Paulo (TJSP), no Superior Tribunal de Justiça (STJ) e no Superior Tribunal Federal (STF) e que contemplassem a palavra "consumidor" em seu corpo de texto. Os resultados desta primeira pesquisa são apresentados na Tabela 2. Além disso,

24 “Art. 42. Na cobrança de débitos, o consumidor inadimplente não será exposto a ridículo, nem será submetido a qualquer tipo de constrangimento ou ameaça.

Parágrafo único. O consumidor cobrado em quantia indevida tem direito à repetição do indébito, por valor igual ao dobro do que pagou em excesso, acrescido de correção monetária e juros legais, salvo hipótese de engano justificável". Disponível em: http://www.planalto.gov.br/ccivil_03/Leis/L8078.htm. Acesso em: 6 jun. 2018.

25 AgRg no REsp 1351546/MG, de 2014. 
buscamos para o mesmo período processos que contivessem a expressão "corte de energia elétrica" e o termo "consumidor". O objetivo era saber qual a parcela de processos consumeristas que ocorreram ocasionados por corte de energia elétrica. O resultado da pesquisa mostrou que, no TJSP, houve 39.488 processos relacionados à consumidor e 6.467 relacionados à corte de energia elétrica. Já no STJ foram 1.875 processos relacionados à consumidor e 206 relacionados à suspensão de energia, no ano de 2017. E, por fim, no STF houve 33 processos relacionados a consumidor e um relacionado à suspensão de energia elétrica.

\section{TABELA 2}

\section{Processos de consumidor versus processos relacionados} à suspensão de energia

(2017)

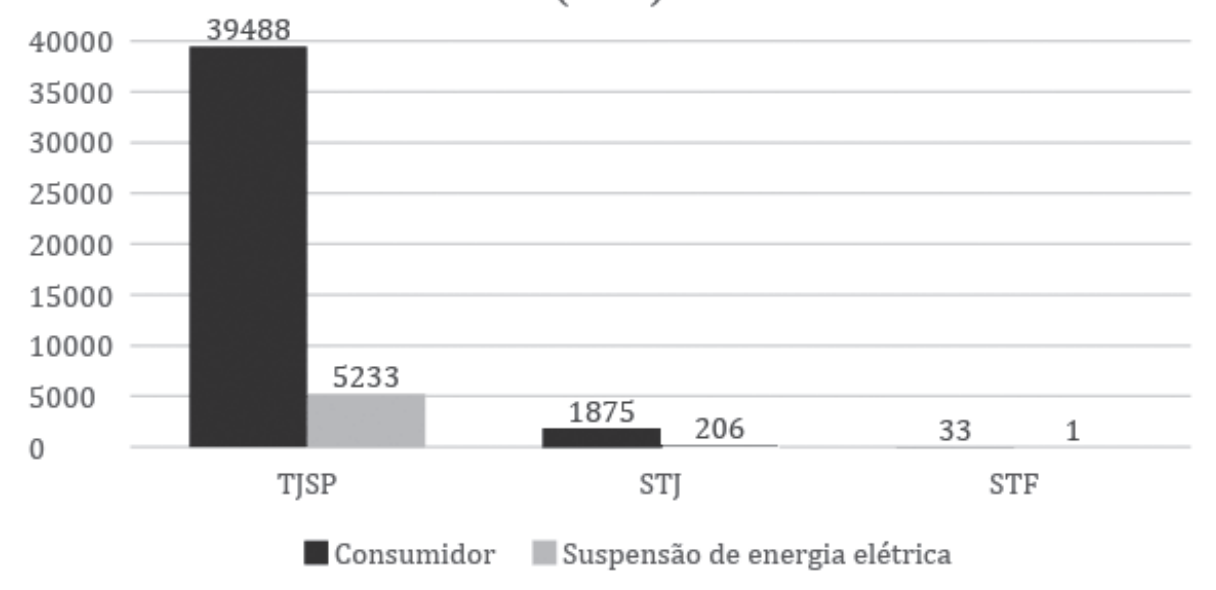

Fonte: Elaboração própria (https://www.digesto.com.br)

Ao analisarmos os dados percentualmente, no Tribunal de Justiça de São Paulo (TJSP) em 2017, 13,3\% dos processos consumeristas tiveram como origem a suspensão de energia elétrica. Já no STJ esse percentual caiu para 11,0\%, enquanto no STF para 3,0\%. É importante mencionar que não foram encontrados resultados da pesquisa por palavras em os outros Tribunais de Justiça, somente em São Paulo.

Um segundo passo a ser tomado é adentrar na pesquisa para tentarmos desvendar qual o peso dos processos relacionados a corte de energia dentro do 
universo dos processos relacionados à energia elétrica. Para tanto, realizamos uma segunda busca no site pela expressão "energia elétrica".

Ainda de acordo com o site Digesto, no ano de 2017, no TJSP, 10.454 são relacionados à energia elétrica de alguma forma, conforme mostrado na Tabela $4{ }^{26}$ Além disso, 6.166 processos são relacionados a corte de energia elétrica. Ou seja, $59 \%$ dos processos de energia elétrica estão diretamente conectados ao corte de energia. Os tribunais dos outros estados da federação não apresentaram nenhum processo relacionado a corte de energia elétrica em 2017. Quando realizamos uma busca federal vemos que em 2017, no STJ, houve 459 processos tratando de energia elétrica, sendo 425 vinculados a corte de energia. Ou seja, $92,6 \%$ dos processos relacionados à energia no STJ no ano de 2017 tem como origem corte de energia elétrica. Por fim, no STF, também em 2017, houve 14 processos sobre energia elétrica. Destes, cinco processos tiveram como origem corte de energia elétrica. Portanto, $35,7 \%$ dos processos estavam vinculados à suspensão de energia elétrica no STF.

TABELA 3

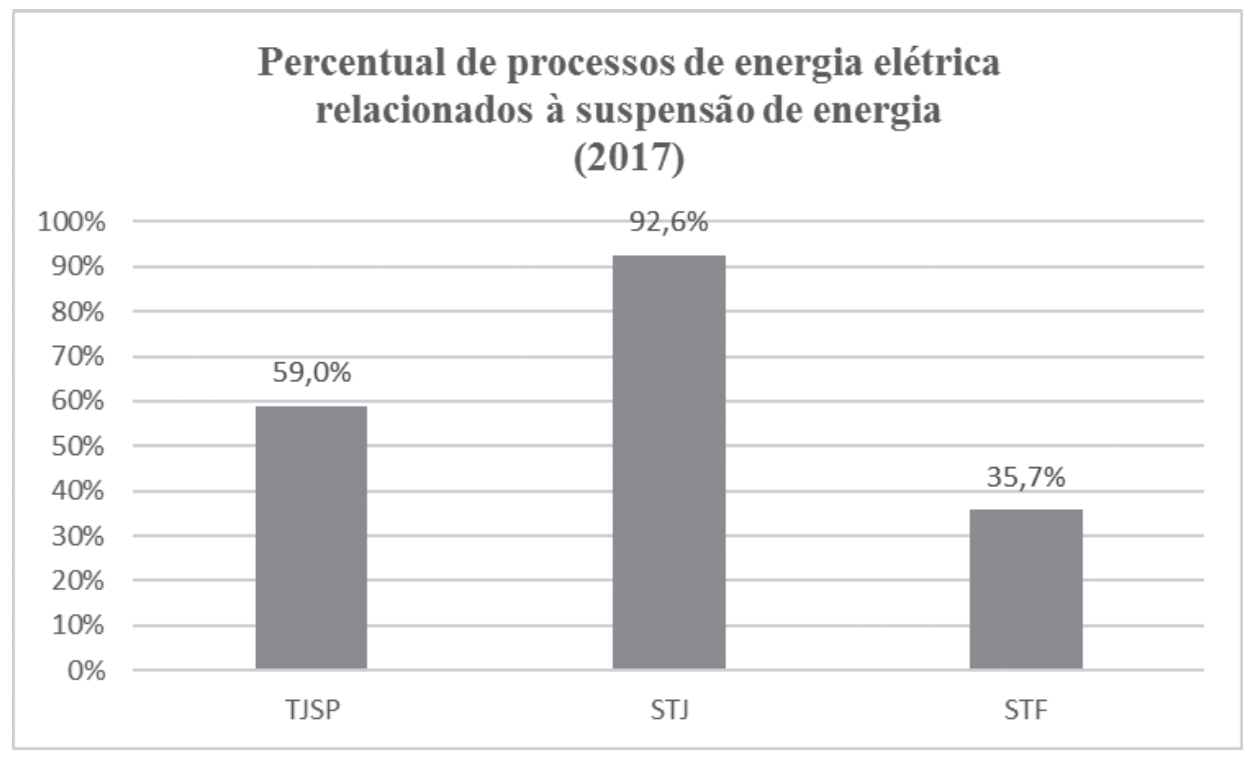

Fonte: Elaboração própria (https://www.digesto.com.br)

26 O site Digesto se dedica a disponibilizar aos usuários da internet informações públicas, com especial enfoque em decisões de tribunais de segunda instância (jurisprudência) e legislação. 
A Tabela 3 mostra o peso referente aos processos relacionados a corte de energia elétrica dentro do universo de processos relacionados à energia elétrica no ano de 2017. O número de maior impacto é o do STJ, onde a quase totalidade dos processos relacionados à energia elétrica tem como origem a interrupção no fornecimento de energia. Os dados descritos demonstram como a questão de interrupção de energia é bastante judicializada, o que de uma forma ou de outra justificaria o temor por parte das distribuidoras de oferecer um sistema de energia pré-paga, no qual a suspensão do serviço tende a ser uma consequência automática do processo de prestação do serviço.

Adicionalmente, analisamos uma segunda base de dados que tem como origem o portal consumidor.gov.br, elaborado pela Secretaria Nacional do Consumidor (Senacon). Essa plataforma permite a mediação de conflitos online de questões consumeristas.

O objetivo ao analisarmos esta base é obter mais informações sobre a questão do comportamento do consumidor mediante o corte de energia elétrica. Dessa forma, os dados que serão apresentados aqui se referem apenas aos fornecedores que estão cadastrados no sistema.

A base de dados conta com 34 segmentos de mercado e um total de 431 fornecedores. A amostra é composta por um milhão, cento e trinta e dois mil e seiscentos e trinta e cinco reclamações, compreendido o período entre maio de 2014 e abril de 2018.

A Tabela 4 mostra os dados do portal consumidor.gov.br. ${ }^{27}$ No ano de $2017,8,4 \%$ das reclamações relacionadas à energia elétrica estão conectadas à interrupção ou instabilidade de fornecimento. Nos anos de 2014, 2015 e 2016 os valores percentuais foram de $13,21 \%, 7,67 \%$ e $9,53 \%$, respectivamente.

27 Disponível em: https://www.consumidor.gov.br/pages/principal/?1528318427832. Acesso em: 6 jun. 2018. 


\section{TABELA 4}

Percentual do Problema "Interrupção/Instabilidade do Fornecimento" no Assunto "Energia Elétrica"

$15,0 \%$

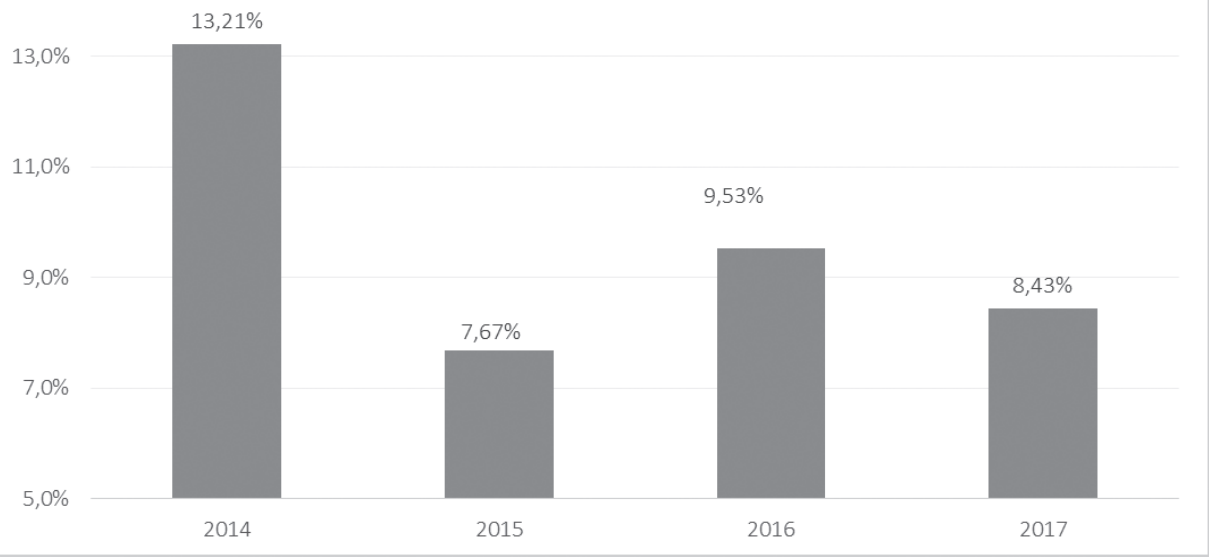

Fonte: Elaboração própria (Consumidor.gov.br)

A Tabela 4 mostra um percentual mais baixo dos que os apresentados na Tabela 3. De um modo geral, este resultado pode ser considerado surpreendente, uma vez que os dados referentes à mediação têm como possível característica serem leading de judicialização. A expectativa é que problemas muito reclamados mais provavelmente também serão judicializados. Existem várias explicações possíveis para este descompasso entre reclamações no portal e a judicialização de fato. A primeira encontra-se na amostra, sugerindo que talvez a amostra do portal consumidor.gov.brnão seja representativa do universo de pessoas que judicializam questões consumeristas. Outra possibilidade se encontra no desconhecimento da população de métodos alternativos de resolução de conflitos, como o próprio site, fazendo com que os agentes afetados recorram diretamente ao Judiciário. Por fim, uma terceira possibilidade seria que, mediante a interrupção de energia elétrica, o consumidor submeta ao Poder Judiciário por supor ter grande probabilidade de ganhar a causa.

Os dados referentes ao Judiciário sugerem que, mesmo mediante tema já pacificado, o a questão da interrupção de energia elétrica ainda se mostra presente nos tribunais em larga escala. De uma forma geral, os dados relativos à judicialização da temática "corte de energia elétrica" impressionam pela 
magnitude. É plausível, portanto, que se esteja diante de receio por parte das empresas responsáveis pela distribuição de energia elétrica de implementar o sistema pré-pago, uma vez que, o corte quase que imediato de energia é uma das características mais marcantes do novo sistema.

\section{Comparação com a telefonia móvel}

Sempre que se examina a modelagem de energia elétrica pré-paga pensa-se na experiência ocorrida com a telefonia móvel. Por isso, nesta seção trataremos das semelhanças e diferenças entre a telefonia móvel e energia elétrica pré-pagas. 0 objetivo reside em compreender a racionalidade por trás do uso do mecanismo de pré-pagamento de outro mercado, que, em que pese suas especificidades, teve a consolidação do uso do cartão pré-pago.

A telefonia pré-paga foi implementada em 1999, na cidade do Rio de Janeiro, com o objetivo de massificar o uso de celulares nas camadas de renda mais baixas da população. De acordo com dados da Agência Nacional de Telecomunicações (ANATEL), a participação do pré-pago em janeiro de 2018 foi de $62,42 \%$ do mercado. ${ }^{28}$

Uma vantagem do celular pré-pago é facilidade de se conseguir um plano em relação ao plano pós-pago, pois não existe verificação de crédito, já que não se abre uma conta. Por outro lado, na energia elétrica, de acordo com a Resolução Normativa ํo 610/2014, art. 5으, §5으, a distribuidora pode condicionar a adesão do consumidor à quitação de débito pendente.

Os planos pré-pagos são boas opções para quem pretende ter um controle maior sobre o quanto deve ser gasto com o aparelho. Nos celulares de conta, caso o usuário extrapole o limite do plano escolhido, corre o risco de ter uma surpresa desagradável no fim do mês. No caso da energia elétrica, essa possibilidade de melhor planejamento dos gastos é uma das principais vantagens apontadas pela ANEEL para justificar a implementação da modalidade no Brasil.

No caso da telefonia móvel, quando o crédito acaba o consumidor pode utilizá-lo parcialmente, ou seja, não faz ligações, mas as recebe. No entanto, na modalidade de pré-pagamento, o consumidor ficará sujeito à suspensão do fornecimento após o esgotamento dos créditos. ${ }^{29}$ Adicionalmente, o consumidor

28 Nota: celulares ativos na operadora. Densidade calculada com a projeção de população do IBGE para o mês respectivo.

29 A distribuidora deve disponibilizar ao consumidor a opção de utilização de um crédito de emergência de no mínimo 20 kWh, o qual deve ser fornecido mediante solicitação ou acionado pelo consumidor diretamente no próprio sistema de medição, conforme definido pela distribuidora. 
tem outras opções de acesso ao serviço de telefonia, caso o crédito do telefone móvel acabe, como o telefone fixo ou público. No caso da energia elétrica, não há alternativa viável.

A questão subjacente quanto à diferenciação entre pré-pagamento de telefonia móvel e eletricidade é a elasticidade. ${ }^{30}$ Provavelmente, a elasticidade do preço da demanda de celular é maior do que a elasticidade do preço da demanda de energia elétrica. Ou seja, quando o preço da ligação fica mais caro, os consumidores respondem diminuindo bastante seu consumo. E quando o preço da energia elétrica fica mais caro, os consumidores respondem menos a essa mudança, alterando muito pouco seu consumo de energia.

\section{Dos fundamentos para a implantação efetiva do sistema pré-pago e os direitos dos consumidores do serviço público de distribuição de energia elétrica}

De maneira geral, a doutrina reconhece a incidência da relação de consumo no uso dos serviços públicos prestados a pessoas físicas que o utilizam como destinatários finais. ${ }^{31}$ Entretanto, para fins de fundamentação jurídica, faz-se necessário expor certa questão doutrinária em relação à extensão e aos limites desta aplicação, em razão de certas peculiaridades dos serviços públicos, tais como a continuidade e a universalidade de sua prestação. ${ }^{32}$

A Lei no 8.987/1995, que estabelece o regime de concessão e permissão de serviços públicos, tais como o serviço de energia elétrica ao qual o presente artigo se refere, faz menção, em seus artigos, ao usuário de serviço público. A título de exemplo, faz-se referência aos arts. 3ำ, 6으 e $7^{\circ}$ da lei, todos mencionando como beneficiário do serviço público o usuário. Entretanto, o CDC (Lei oㅛ 8.078/1990), lei anterior àquela que dispõe sobre o regime de concessões e permissões, estabeleceu, em seu art. 6으, X, que o consumidor tem direito à adequada prestação de serviço público. Anos depois, o art. 7ํ da Lei o 8.987/1995 foi alterado, sendo incluído o art. 7--, incluindo tanto os consumidores como os beneficiários do serviço público prestado por entidades privadas.

30 Elasticidade é o tamanho do impacto que a alteração em uma variável (ex.: preço) exerce sobre outra variável (ex.: demanda).

31 PFEIFFER, Roberto Augusto Castellanos. Serviços Públicos Concedidos e Proteção do Consumidor. In: Revista de Direito do Consumidor, v. 36, jan./mar., 2001.

32 Segundo Alexandre Aragão, "O CDC não pode ser aplicado indiscriminadamente aos serviços públicos, já que eles não são atividades econômicas comuns, sujeitas à liberdade de empresa e desconectadas da preocupação de manutenção de um sistema prestacional coletivo" (ARAGÃo, Alexandre. Curso de Direito Administrativo. Rio de Janeiro: Forense, 2011, p. 520-521). 
Nesse contexto, apesar de atualmente a Lei no 8.987/1995 fazer referência também ao $\mathrm{CDC}$, é preciso diferenciar as categorias consumidor e usuário. As diferenças encontram-se, por exemplo, na própria natureza da atividade, uma vez que as relações consumeristas são tipicamente privadas, ao passo que a relação entre um usuário do serviço público e a concessionária do serviço é também influenciada pelo contrato que esta última mantém com o poder concedente, para o qual o usuário pode recorrer. Ainda, ao passo que os usuários de serviço público remuneram a empresa mediante tarifas, nas típicas relações de consumo não existem tarifas, mas sim preços privados.

Em suma, a doutrina entende que o CDC de fato se aplica à relação entre usuários e prestadores de serviço, mas de forma subsidiária. Isso significa que, caso haja lei específica do setor de um serviço público específico e regulamento da respectiva agência fiscalizadora, a regra é que a estas normas seja dada prioridade. ${ }^{33}$ Dessa forma, reafirma-se que, atualmente, o que está em questão é a extensão da incidência do CDC e não sua aplicação em si.

Considerando a incidência do CDC no fornecimento dos serviços públicos, é inafastável a ideia de que as relações de consumo devem ser pautadas pelos princípios da boa-fé, da transparência, do respeito à dignidade do consumidor e da proteção dos direitos econômicos, os quais podem levar a interpretações de serem desrespeitados pelas concessionárias quando submetem seus consumidores ao constrangimento de suspensão de energia elétrica em suas residências, de forma impositiva, causando a privação de um serviço essencial, não só para os afazeres habituais de uma residência, mas também de trabalho.

De acordo com o CDC, o serviço de energia elétrica é um bem essencial à população e a sua supressão de forma arbitrária pode ser considerado uma agressão ao direito do cidadão de utilizar um serviço público tão necessário para a vida em sociedade.

A Constituição Federal, em seu art. 21, inc. XII, "b", coloca a energia elétrica como um dos principais serviços públicos oferecidos à população. A transferência da execução de serviço público econômico ${ }^{34}$ da Administração Pública indireta, por meio de suas empresas estatais, para a iniciativa privada, por meio de concessionárias e permissionárias, não modifica o direito dos usuários do serviço, que com o advento do CDC, tiveram reforçados e ampliados seus direitos.

33 GUERRA, Sérgio Transformações do Estado e do direito: novos rumos para o poder judiciário. Rio de Janeiro: FGV Editora, 2015, v. 2.

34 “Um serviço é caracterizado como econômico quando enseja que o prestador obtenha lucros com a execução desse serviço. Exemplos seriam os serviços de energia elétrica, gás canalizado, transportes coletivos. Os serviços públicos econômicos podem ser prestados por entes da Administração Pública Indireta, como empresas públicas e sociedades de economia mista, assim como por empresas privadas 
É dever das concessionárias oferecer o serviço público de modo contínuo e regular, tendo responsabilidade objetiva pelos danos que vierem a causar aos consumidores, conforme estabelece o §6ำ do art. 37 da Constituição: "As pessoas jurídicas de direito público e as de direito privado prestadoras de serviços públicos responderão pelos danos que seus agentes, nessa qualidade, causarem a terceiros."

Como já mencionado, há relação contratual entre as empresas concessionárias e os particulares consumidores, a qual é principalmente regida pelo CDC, que no seu art. 22 dispõe que: “os órgãos públicos, por si ou suas empresas, concessionárias, permissionárias ou sob qualquer outra forma de empreendimento, são obrigados a fornecer serviços adequados, eficientes, seguros e, quanto aos essenciais, contínuos." E no seu parágrafo único, estabelece que: "nos casos de descumprimento, total ou parcial, das obrigações referidas neste artigo, serão as pessoas jurídicas compelidas a cumpri-las e a reparar os danos causados, na forma prevista neste Código."

Porém, conforme mencionado no terceiro subtítulo, o tema já foi pacificado. Tanto as leis ordinárias quanto as resoluções editadas pela ANEEL são uníssonas em admitir a suspensão do fornecimento de energia elétrica mediante a falta de pagamento pelo consumidor. Assim, seria de se esperar que o fato de o sistema de energia pré-paga tornar mais célere a suspensão da energia elétrica não seria um problema para as distribuidoras, dada a pacificação do tema. Exatamente por isso, no presente artigo sugerimos que a atual resistência das concessionárias em implementar o sistema pode ser decorrente do receio judicialização da interrupção de energia elétrica, como será observado adiante.

Um estudo publicado em 2015 pela FGV Direito Rio a pedido da concessionária de energia elétrica Light, da cidade do Rio de Janeiro, se propôs a analisar dados sobre processos que tramitavam em Câmaras Cíveis e Juizados Especiais Cíveis, constatando os fatos apresentados na Tabela 6 na relação entre concessionárias e usuários. ${ }^{35}$

pelo regime de delegação (CARVALHO FILHO, José dos Santos. Manual de Direito Administrativo. 32. ed. rev., atual. e ampl. São Paulo: Atlas, 2018).

35 WADA, Ricardo Morishita (Coord.). Mapeamento dos conflitos de consumo de energia elétrica: Um estudo de caso no estado do Rio de Janeiro. Rio de Janeiro: Escola de Direito do Rio de Janeiro da Fundação Getulio Vargas, 2015. Disponível em: https://bibliotecadigital.fgv.br/dspace/bitstream/handle/10438/13974/Mapeamento\%20dos\%20 conflitos\%20de\%20consumo\%20de\%20energia\%20el\%C3\%A9trica.pdf. Acesso em: 6 jun. 2018. 


\section{TABELA 6}

\begin{tabular}{|c|c|}
\hline 1 & Suspensão do fornecimento sem suporte probatório convincente da irregularidade ("corte indevido") \\
\hline 2 & Cobrança de valores por suposta irregularidade no medidor que não res tou comprovada \\
\hline 3 & Cobrança indevida em razão de troca de titularidade \\
\hline 4 & $\begin{array}{l}\text { Ausência de perícia no medidor que a concessionária alega estar viciado impediria confirmar a } \\
\text { existência de defeito no aparelho medidor ou o envolvimento do consumidor na fraude }\end{array}$ \\
\hline 5 & $\begin{array}{l}\text { Troca do medidor antes da produção da prova impossibilitaria a perícia ou mesmo a simples } \\
\text { contestação dos fatos }\end{array}$ \\
\hline 6 & $\begin{array}{l}\text { Instalação de medidor em área externa e constatação de fraude fora da residência; impedimento } \\
\text { físico de acesso por parte do consumidor e, portanto, impossibilidade de sua responsabilização } \\
\text { em caso de fraude }\end{array}$ \\
\hline 7 & $\begin{array}{l}\text { Falha na prestação do serviço por parte da concessionária, como situação em que a deficiência na } \\
\text { alimentação ao ramal localizado no pos te levou a registro de consumo aquém do esperado, não } \\
\text { sendo fato imputável ao usuário; }\end{array}$ \\
\hline 8 & Suspensão do serviço sem prévio aviso \\
\hline 9 & $\begin{array}{l}\text { Unilateralidade do TOI (Termo de Ocorrência e Inspeção): documento preenchido unilateralmente } \\
\text { pela concessionária não permitiria contraprova ou qualquer providência alusiva ao contraditório, à } \\
\text { ampla defesa ou à transparência }\end{array}$ \\
\hline
\end{tabular}

Fonte: Elaboração Própria (Wada, 2015)

De acordo com o estudo, um dos aspectos jurídicos que gera muita controvérsia nas decisões que envolvem disputas entre usuários e concessionárias de energia elétrica no Tribunal de Justiça do Rio de Janeiro (TJRJ) consiste justamente na possibilidade de as concessionárias suspenderem o serviço. Portanto, uma das hipóteses a ser considerada seria de que as decisões judiciais incentivam a litigância entre usuários e concessionárias.

Outra hipótese levantada pelo estudo seria a de que o Poder Judiciário também contribuiria com o cenário de judicialização ao condenar excessivamente as concessionárias por dano moral, o que incentivaria os usuários à litigância mesmo quando não há comprovação da falha do serviço da concessionária ou de prejuízo ou lesão ao consumidor.

Ambas as hipóteses apresentadas pelo estudo vão ao encontro dos achados da pesquisa materializada neste artigo. Ou seja, infere-se que o maior empecilho à implementação do pré-pagamento de energia elétrica no Brasil seja a insegurança jurídica decorrente de um histórico de judicialização de temas relacionados à suspensão do serviço no sistema pós-pago. Dito de outra forma, por mais que já haja pacificação do tema que envolve a suspensão de energia elétrica por falta de pagamento, é plausível inferir haver uma percepção por parte das distribuidoras de 
que o Poder Judiciário tenderia a proteger os consumidores nessa relação, e que a forma abrupta como ocorre a suspensão do serviço nos casos de energia prépaga, por sistema pré-pago, poderia ser compreendida como ofensa a princípios de proteção aos consumidores e à dignidade da pessoa humana.

Acrescenta-se que essa percepção das empresas distribuidoras pode ser corroborada com a análise das contribuições trazidas pelos consumidores na Consulta Pública o 16/2017 e consolidadas em uma Nota Técnica pela ANEEL. Segundo os depoimentos, o maior problema dos consumidores é justamente o fato de que a implementação do sistema pré-pago de energia elétrica tornaria a suspensão desta muito mais rápida, em razão da necessidade de adquirir novos créditos para reaver o fornecimento de energia elétrica. Alegou-se, ainda, que essa necessidade afetaria diretamente os consumidores de baixa-renda que teriam dificuldade em adquirir novos créditos com rapidez: "Os consumidores de baixa renda, como no meu caso, serão os mais vulneráveis por falta de capacidade de adquirir novos créditos rapidamente." 36

A questão, portanto, está afeta à função de regulação, dotada de estrutura necessária para equilibrar o sistema regulado (de distribuição de energia elétrica), suprir as falhas do mercado, mediar e ponderar os diversos interesses ambivalentes. Ela tem melhores condições, do ponto de vista jurídico, de enfrentar os desafios da reflexividade da vida social.

\section{Conclusão}

A ANEEL abriu uma consulta pública em dezembro de 2017, com o objetivo de aprimorar e discutir junto à sociedade o pré-pagamento de energia elétrica no Brasil. A experiência internacional apresenta casos de sucesso, com uma variedade de companhias de energia que implementaram o programa de fornecimento de energia elétrica pré-paga em funcionamento. No entanto, no Brasil, o mecanismo de pré-pagamento ainda se mostra praticamente inoperante, mesmo com a regulação de sua instituição com a edição da Resolução no 610/2014 da ANEEL.

$\mathrm{O}$ não oferecimento do serviço pré-pago de energia elétrica, em que pese a normatização, aponta, sob a óptica econômica (análise de custos e benefícios), não ser vantajoso para as concessionárias. Nesse sentido, e considerando todas as informações e dados coletados, os antecedentes e projeto-piloto, a análise jurisprudencial comprovando a juridicidade do corte do fornecimento de energia

36 Nota Técnica no 0072/2018-SRD/ANEEL, de 29.06.2018. Acesso em: 12 set. 2018. 
elétrica por inadimplemento do consumidor, pode-se concluir pela confirmação da hipótese apresentada neste artigo.

Com efeito, o receio de judicialização explica certa resistência, por parte das empresas, em ofertar o serviço de fornecimento de energia elétrica pré-paga. $\mathrm{Na}$ pesquisa jurisprudencial foi possível apurar que, em diferentes amostras de processos concluídos em 2017, parcela significativa dos processos envolvendo o serviço de distribuição de energia elétrica está diretamente relacionada à interrupção (corte) de fornecimento, favorecendo a insegurança jurídica por parte das empresas responsáveis pela distribuição de energia elétrica.

É assinalável que a nova modalidade de cobrança do fornecimento de energia elétrica afetará de forma diversa as várias camadas da sociedade. De acordo com Dantas et al (2016), a região brasileira considerada mais pobre está mais propensa a mudanças ocorridas na tarifa de energia elétrica, enquanto, no caso contrário, as regiões consideradas mais desenvolvidas estariam menos propensas a alterar seu consumo mediante mudanças na tarifa de energia. ${ }^{37}$

O resultado quanto à implementação desse novo modelo dependerá de como será o estruturado o processo e qual será a relação econômica da tarifa prépaga com a atual (pós-paga). Caso a tarifa pré-paga seja mais baixa, haverá uma tendência à migração de consumidores de baixa renda para a nova modalidade. Talvez a migração seja favorecida pelo disposto na Resolução ANEEL no 610/2014 quanto à existência de uma tarifa social para aqueles consumidores de energia elétrica pré-paga que sejam de baixa renda. Nesse sentido, o item 23, cláusula segunda, do contrato de fornecimento de energia pré-paga anexado à Resolução dispõe ser direito dos consumidores desse sistema "ser informado sobre o direito à Tarifa Social de Energia Elétrica - TSEE e sobre os critérios e procedimentos para a obtenção de tal benefício, se for o caso." ${ }^{38}$

Sob essa perspectiva, conclui-se que havendo excesso de rigidez normativa e, notadamente, decisões judiciais “pró" consumidor, esse fato pode, sob a óptica sistêmica, afetar o próprio direito dele, consumidor, na medida em que pode inviabilizar, economicamente, a criação de novos serviços ou novas modalidades de prestação que serviriam justamente ao seu benefício.

Daí a importância da função de regulação, que se fundamenta na atuação do Estado sobre decisões e atuações empresariais de forma adequada, necessária e proporcional, com fundamentos técnicos e científicos que visem a atender ao

DANTAS, Fabiano; COSTA, Edward; SILVA, Jorge Luiz Mariano da. Elasticidade preço e renda da demanda por energia elétrica nas regiões brasileiras: uma abordagem através de painel dinâmico. In: Revista de Economia, ano 40, v. 43, n. 3, set./dez. 2016. Disponível em: https://revistas.ufpr.br/economia/article/ view/36594. Acesso em: 12 set. 2018.

38 Disponível em http://www2.aneel.gov.br/cedoc/ren2014610.pdf. Acesso em: 12 set. 2018. 
interesse público substantivo sem, contudo, deixar de sopesar os efeitos dessas decisões no subsistema regulado com os interesses de segmentos da sociedade e mesmo com o interesse individual (consumidor) no caso concreto.

\section{Regulation of prepaid energy in Brazil and consumers rights}

Abstract: The modality of providing the prepaid public energy distribution service has been successfully implemented in international experience, following new technologies and innovations. This has been presented as an interesting modality of tariff collection because it presents considerable advantages for companies and for users / consumers, mainly because it brings greater predictability in the value of the consumption account, besides presenting a greater rationality in the consumption of electric energy. In Brazil, this modality of tariff collection was regulated in 2014 by regulations issued by the National Electric Energy Agency (ANEEL). The concessionaires did not implement this modality of tariff collection. The hypothesis examined in this article, under an economic and legal bias, is that the nonimplementation is due to the high risk anticipated by the suppliers that, in case of suspension of the electricity distribution service, for non-payment, consumers will question judicially the interruption of the service due to fundamental rights. If the hypothesis is proven, on an empirical basis, this phenomenon would confirm the idea that there is a direct correlation between the overprotection of consumer rights and the negative effects caused to them, which would justify the importance of the regulation function for the maintenance of the systemic balance.

Keywords: Public service. Regulation. Electricity. Prepayment. Consumer right.

Summary: $\mathbf{1}$ Introduction - $\mathbf{2}$ Pilot project of the prepaid electric energy system in Brazil - $\mathbf{3}$ Economic evidence on the adoption of the prepaid system on business revenue and consumption - 4 Data from the Brazilian context on the judicialization of the topic suspension of electric power consumption due to default - $\mathbf{5}$ Comparison with mobile telephony - $\mathbf{6}$ Grounds for the effective implementation of the prepaid system and the rights of consumers of public electricity distribution service $\mathbf{7}$ Conclusion References.

\section{Referências}

BAPTISTA, Idalina. 'We Live on Estimates': Everyday Practices of Prepaid Electricity and the Urban Condition in Maputo, Mozambique. In: International Journal of Urban and Regional Research, v. 39, n. 5, p. 1004-1019, 2015. BRUTSCHER, Philipp-Bastian. Payment Matters? An Exploratory Study into the Pre-Payment Electricity Metering. 2011. In: Working Paper EPRG1108. Cambridge, UK: Electricity Policy Working Group, Cambridge University. CASARIN, Ariel; NICOLLIER, Luciana. Prepaid meters in electricity. A cost-benefit analysis. In: MARQUEZ, Patricia; RUFIN, Carlos (Coord.). Private Utilities and Poverty Alleviation: Market Initiatives at the Base of the Pyramid. Williston, USA: Edward Elgar Publishing Inc, 2011. CARVALHO FILHO, José dos Santos. Manual de Direito Administrativo. 32. ed. rev., atual. e ampl. São Paulo: Atlas, 2018 
DANTAS, Fabiano; COSTA, Edward; SILVA, Jorge Luiz Mariano da. Elasticidade preço e renda da demanda por energia elétrica nas regiões brasileiras: uma abordagem através de painel dinâmico. In: Revista de Economia, ano 40, v. 43, n. 3, set./dez. 2016. ESTEVES, Gheisa Roberta Telles; OLIVEIRA, Fernando Luiz Cyrino; ANTUNES, Carlos Henggeler; SOUZA, Reinaldo Castro. An overview of electricity prepayment experiences and the Brazilian new regulatory framework. In: Renewable and Sustainable Energy Reviews, v. 54, p. 704-722, 2016. GUERRA, Sérgio. Discricionariedade, regulação e reflexividade: uma nova teoria sobre as escolhas administrativas. 5. ed. Belo Horizonte: Fórum, 2018.

MALAMA, Albert; MUDENDA, Priscilla; NG'OMBE, Austine; MAKASHINI, Lilias; ABANDA, Henry. The Effects of the Introduction of Prepayment Meters on the Energy Usage Behaviour of Different Housing Consumer Groups in Kitwe, Zambia. In: AIMS Energy, v. 2, n. 3, p. 237-259, 2014. PFEIFFER, Roberto Augusto Castellanos. Serviços Públicos Concedidos e Proteção do Consumidor. In: Revista de Direito do Consumidor, v. 36, jan./mar., 2001.

SALINAS, Natasha; MARTINS, Fernanda. Os Mecanismos de Participação da Agência Nacional de Saúde Suplementar (ANS). No prelo.

WADA, Ricardo Morishita (Coord.). Mapeamento dos conflitos de consumo de energia elétrica: Um estudo de caso no estado do Rio de Janeiro. Rio de Janeiro: Escola de Direito do Rio de Janeiro da Fundação Getulio Vargas, 2015. WADA, Ricardo Morishita (Coord.). Os conflitos, a regulação e o direito do consumidor. Rio de Janeiro: Escola de Direito do Rio de Janeiro da Fundação Getulio Vargas, 2015.

Informação bibliográfica deste texto, conforme a NBR 6023:2018 da Associação Brasileira de Normas Técnicas (ABNT):

GUERRA, Sérgio; NOGUEIRA, Rafaela. Regulação da energia pré-paga no Brasil e os direitos dos consumidores. Direitos Fundamentais \& Justiça, Belo Horizonte, ano 13, n. 40, p. 239-264, jan./jun. 2019.

Recebido em: 17.10.2018

Pareceres: 14.02.2019 e 17.02.2019

Aceito para publicação: 22.02.2019 